TUBERCULOSIS

\title{
Risk factors for multidrug resistant tuberculosis in Europe: a systematic review
}

\author{
A Faustini, A J Hall, C A Perucci
}

See end of article for authors' affiliations ......................

Correspondence to: Dr A Faustini, Department of Epidemiology, RME, 00198 Rome, Italy: faustini@asplazio.it

Received 27 April 2005 Accepted 18 October 2005 Published Online First 27 October 2005 in western countries has been attributed to the HIV Background: The resurgence of tuberculosis (TB) in western countries has been attributed to the HIV transmission of multidrug resistant Mycobacterium tuberculosis strains in new cases, or by the selection of single drug resistant strains induced by previous treatment. The aim of this report is to determine risk factors for MDR-TB in Europe.

Methods: A systematic review was conducted of published reports of risk factors associated with MDR-TB in Europe. Meta-analysis, meta-regression, and sub-grouping were used to pool risk estimates of MDR-TB and to analyse associations with age, sex, immigrant status, HIV status, occurrence year, study design, and area of Europe.

Results: Twenty nine papers were eligible for the review from 123 identified in the search. The pooled risk of MDR-TB was 10.23 times higher in previously treated than in never treated cases, with wide heterogeneity between studies. Study design and geographical area were associated with MDR-TB risk estimates in previously treated patients; the risk estimates were higher in cohort studies carried out in western Europe (RR 12.63; 95\% Cl 8.20 to 19.45) than in eastern Europe (RR 8.53; $95 \% \mathrm{Cl} 6.57$ to 11.06). National estimates were possible for six countries. MDR-TB cases were more likely to be foreign born (odds ratio (OR) $2.46 ; 95 \% \mathrm{Cl} 1.86$ to 3.24 ), younger than 65 years (OR $2.53 ; 95 \% \mathrm{Cl} 1.74$ to 4.83), male (OR 1.38; $95 \% \mathrm{Cl} 1.16$ to 1.65 ), and HIV positive (OR $3.52 ; 95 \% \mathrm{Cl} 2.48$ to 5.01 ).

Conclusions: Previous treatment was the strongest determinant of MDR-TB in Europe. Detailed study of the reasons for inadequate treatment could improve control strategies. The risk of MDR-TB in foreign born people needs to be re-evaluated, taking into account any previous treatment.
$\mathrm{T}$ he resurgence of tuberculosis (TB) in western countries was first recognised in the USA in 1986 when TB notifications increased, reversing the decreasing trend observed for many years. ${ }^{1}$ The rate of TB cases also increased in the 1980s in European countries such as the Netherlands, Switzerland, Norway, and Denmark. ${ }^{2}$

The reason for this increase in the USA was initially attributed to the HIV epidemic and to the growth of poverty in urban settings. ${ }^{3}$ However, other factors emerged over time: (1) cases among recent immigrants from developing countries comprised a growing percentage of TB notifications; ${ }^{24}$ (2) many cases were reported to be drug resistant and multidrug resistant (MDR-TB); ${ }^{5}$ (3) control practices were neglected in some countries as a consequence of inadequate resources, political instability, or the reduced importance of TB in public health. ${ }^{6}$

MDR-TB is defined as tuberculosis resistant to at least isoniazid $(\mathrm{H})$ and rifampicin $(\mathrm{R})$. Inadequate drug treatment of an individual with TB will kill the majority of their bacteria but will permit the growth of the small number of resistant organisms within that bacterial population which are arising by spontaneous mutation. A population wholly resistant to a single drug then emerges, and continuing inadequate treatment goes on to select from among this population the small number of organisms which have mutated to have further drug resistance. Resistance to one drug may therefore become resistance to two drugs, and then sequentially to many drugs.

MDR-TB cases may thus arise by direct transmission of an MDR strain from one individual to another, but also by inadequate treatment of an individual who was initially infected by a fully sensitive strain, or one with only single drug resistance. However it occurs, MDR-TB challenges tuberculosis control, because standardised short course chemotherapy (SS-CC) is less effective in these patients ${ }^{7}$ and second line drugs are less effective and more toxic than first line drugs. ${ }^{8}$

Either transmission of MDR strains or selection of single drug resistant strains may have contributed to the increase in the prevalence of MDR-TB in western countries. Infectivity of MDR strains is higher than was initially thought. The prevalence of infection among contacts of MDR-TB cases is similar to the prevalence among contacts of cases without MDR-TB. ${ }^{10}$ In closed communities such as prisons and hospitals, MDR-TB has been transmitted between immunocompetent as well as immunodeficient individuals. ${ }^{11}{ }^{12}$ The selection of single drug resistant strains of Mycobacterium tuberculosis is attributable only to inadequate treatment since alternative mechanisms such as the presence of plasmids or other genetic elements has never been demonstrated for TB. ${ }^{13}$

Unsuccessful treatment therefore plays a double role with respect to $\mathrm{MDR}-\mathrm{TB}$ - it can be either a result of, or a risk factor for, MDR-TB. These relationships are so widely recognised that MDR-TB is classified as being due to previous treatment if the patient has been treated before, and attributed to an infection with an MDR strain of $M$ tuberculosis if detected in newly diagnosed patients. ${ }^{6}$

The World Health Organisation (WHO) has documented MDR-TB worldwide. According to the most recent data, between 1999 and 2002 the prevalence of MDR-TB was 1.7\% in all cases, $1.1 \%$ in new cases, and $7 \%$ in previously treated cases. ${ }^{6}$ A few countries in eastern Europe and in southeast Asia are areas of concern for the dissemination of MDR-TB because drug resistant strains may be continuously created

Abbreviation: MDR-TB, multidrug resistant tuberculosis 
and circulated, as suggested by the high percentages of multidrug resistance among both new and previously treated cases.

Although many studies in Europe have focused on the prevalence of MDR-TB, only a few have dealt with risk factors and have analysed multidrug resistance separately from other drug resistances. We report here the results of a systematic review to determine the risk factors associated with MDR-TB in Europe.

\section{METHODS}

\section{Identification and selection of papers}

A systematic review of published reports dealing with risk factors for MDR-TB in Europe was carried out. Studies were identified through a computerised search of the following databases: PubMed (1993-2003), Embase (1993-2003), Toxline (1993-2003), Serfile (1998-2003), CAB abstract (1993-2003). Medline was searched through PubMed. The search terms tuberculosis, drug resistance, and multidrug resistance and any of the following-risk factors, epidemiologic determinants, predictors, treatment-outcome, treatment failure, surveillance, surveys, transmission, and spreadingwere used as a combination of free text and thesaurus terms in different variations. The documents produced on the WHO website were systematically searched. The International Journal of Tuberculosis and Lung Disease was selected as the key journal for hand searching.

Reports of original studies from European countries were included in the review, while comments, editorials and reviews were excluded. Articles were included if they contained information allowing estimates of association between MDR-TB and risk factors. We did not report variables associated with MDR-TB as clinical predictors such as cavitary disease.

Articles were excluded if they had $<10$ cases or only extrapulmonary TB, if they dealt with a Mycobacterium other than tuberculosis, if they were limited to high risk groups such as HIV positive or neoplastic patients or prisoners, or if they were limited to a particular outbreak. We also excluded case reports and studies presenting results on diagnostic/ laboratory methods, drug efficacy tested in vitro or through clinical trials, TB vaccination, indications for management or treatment of MDR-TB, and surgical management of resistant tuberculosis.

\section{Outcomes measures and definitions}

MDR-TB was defined in each paper as tuberculosis resistant to at least isoniazid and rifampicin (HR). The study population was estimated as the number of TB patients with a positive culture for $M$ tuberculosis who underwent drug sensitivity analysis. European countries were selected according to the WHO regional classification, which includes Israel and Turkey.

\section{Statistical analysis}

Where appropriate, we used pooled risk estimates, odds ratios (ORs), and relative risks (RRs) of MDR-TB in a random effects meta-analysis (Stata Version 7). We included in pooled ORs the risk estimates obtained in all surveys, irrespective of study design. The standard error and 95\% confidence intervals (CI) of risk estimates were calculated from data reported in each paper. We assessed heterogeneity between studies by using the $\chi^{2}$ test, and variation due to heterogeneity across the studies by calculating the $\mathrm{I}^{2}$. The factors we analysed to determine the association with MDRTB were previous treatment, foreign born status, HIV status, age under 45 , age under 65 , and male sex. Whenever possible we stratified the results by country or geographical area of Europe. A regression analysis by year of TB occurrence, study design, and the proportions of patients at risk for other factors was performed.

\section{RESULTS}

Of 1721 articles selected from the initial PubMed search on MDR-TB risk factors, 119 were from European countries. No additional references were identified from the other

Table 1 Risk estimates of MDR-TB for factors reported in original studies (incomplete data)

\begin{tabular}{|c|c|c|c|c|c|c|}
\hline Reference & Time/place & Design & $\begin{array}{l}\text { Population } \\
\text { studied* } \\
\mathrm{N}(\%)\end{array}$ & $\begin{array}{l}\text { No of } \\
\text { MDR-TB } \\
\text { cases }\end{array}$ & Factors &  \\
\hline Lockman $^{14}$ & $\begin{array}{l}\text { 1994-1996, } \\
\text { Estonia }\end{array}$ & $\begin{array}{l}\text { Matched case-control } \\
\text { study }\end{array}$ & $833(\mathrm{nr})$ & 46 & Female sex & OR 3.5 (1.1 to 14.6$)$ s \\
\hline Gilad $^{15}$ & $\begin{array}{l}\text { 1992-1997, } \\
\text { Negev, Israel }\end{array}$ & $\begin{array}{l}\text { Retrospective laboratory } \\
\text { based survey }\end{array}$ & 249 (nr) & 21 & $\begin{array}{l}\text { Immigrants from former } \\
\text { Soviet Union }\end{array}$ & OR 4.10 (1.48 to 11.83$)$ \\
\hline Anon $^{16}$ & $\begin{array}{l}\text { 1995-1998, } \\
\text { Ivanovo, Russia }\end{array}$ & $\begin{array}{l}\text { Frequency matched } \\
\text { case-control study }\end{array}$ & $\begin{array}{l}514(\mathrm{nr}) \\
\text { new cases }\end{array}$ & 26 & Homelessness & OR 3.1 (1.1 to 8.8$)$ \\
\hline Flament-Saillour $^{17}$ & 1994, France & $\begin{array}{l}\text { Laboratory based } \\
\text { case-control study }\end{array}$ & $7752(\mathrm{nr})$ & 51 & $\begin{array}{l}\text { Previous treatment } \\
\text { Foreign born }\end{array}$ & $\begin{array}{l}\text { OR } 24.2(6.9 \text { to } 85.1)^{* *}+\dagger \\
\text { OR } 3.8(1.2 \text { to } 11.8)^{* *}+\dagger\end{array}$ \\
\hline Kimerling $^{18}$ & $\begin{array}{l}\text { 1999, Tomsk City, } \\
\text { Siberia, Russia }\end{array}$ & $\begin{array}{l}\text { Retrospective laboratory } \\
\text { based survey }\end{array}$ & $\begin{array}{l}244(\mathrm{nr}) \\
\text { new cases }\end{array}$ & 32 & $\begin{array}{l}\text { Age } \leqslant 40 \text { years } \\
\text { Male sex } \\
\text { Unemployment } \\
\text { Good residence } \neq \ddagger \\
\text { Prison history ( } 10 \text { years) } \\
\text { Drug addiction } \\
\text { Psychological disorders }\end{array}$ & $\begin{array}{l}\text { OR } 1.2(0.6 \text { to } 2.5) \\
\text { OR } 0.9(0.4 \text { to } 1.9) \\
\text { OR } 0.8(0.3 \text { to } 1.8) \\
\text { OR } 2.1(1.0 \text { to } 4.7) \\
\text { OR } 1.4(0.6 \text { to } 3.4) \\
\text { OR } 1.9(0.5 \text { to } 7.2) \\
\text { OR } 2.6(0.8 \text { to } 8.8)\end{array}$ \\
\hline Migliori $^{29} \ddagger$ & $\begin{array}{l}\text { 1998-1999, } \\
\text { Italy }\end{array}$ & $\begin{array}{l}\text { Retrospective laboratory } \\
\text { based survey }\end{array}$ & $810(30)$ & 51 & $\begin{array}{l}\text { Previous treatment among } \\
\text { treated cases age } \leqslant 45 v \\
>45 \text { years }\end{array}$ & RR 1.88 (1.31 to 2.70$)$ \\
\hline Fietta $^{30} \mp$ & $\begin{array}{l}\text { 1990-2000, } \\
\text { Pavia, Italy }\end{array}$ & $\begin{array}{l}\text { Retrospective population } \\
\text { based survey }\end{array}$ & $279(\mathrm{nr})$ & 39 & $\begin{array}{l}\mathrm{HIV+} \\
\text { Immigration }\end{array}$ & $\begin{array}{l}\text { OR } 14.2(3.5 \text { to } 57.4) \\
\text { OR } 3.9(1.2 \text { to } 12.6)\end{array}$ \\
\hline \multicolumn{7}{|c|}{$\begin{array}{l}\text { MDR-TB, multidrug-resistant tuberculosis; OR, odds ratios; RR, relative risk; Cl, confidence intervals; nr, not reported. } \\
\text { *The number of confirmed cases of TB further tested for drug sensitivity. } \\
\text { †Versus drug susceptible and other resistant TB if not otherwise specified. } \\
\text { †The risk of MDR-TB for previous treatment has been included in meta-analysis as complete data were available. } \\
\text { §Versus drug susceptible TB. } \\
\text { TMatched for date and region of notification. } \\
\text { * Versus other cases resistant to more than one drug. } \\
\text { ††Multivariable analysis. } \\
\text { ††Defined as having a permanent place to live. }\end{array}$} \\
\hline
\end{tabular}




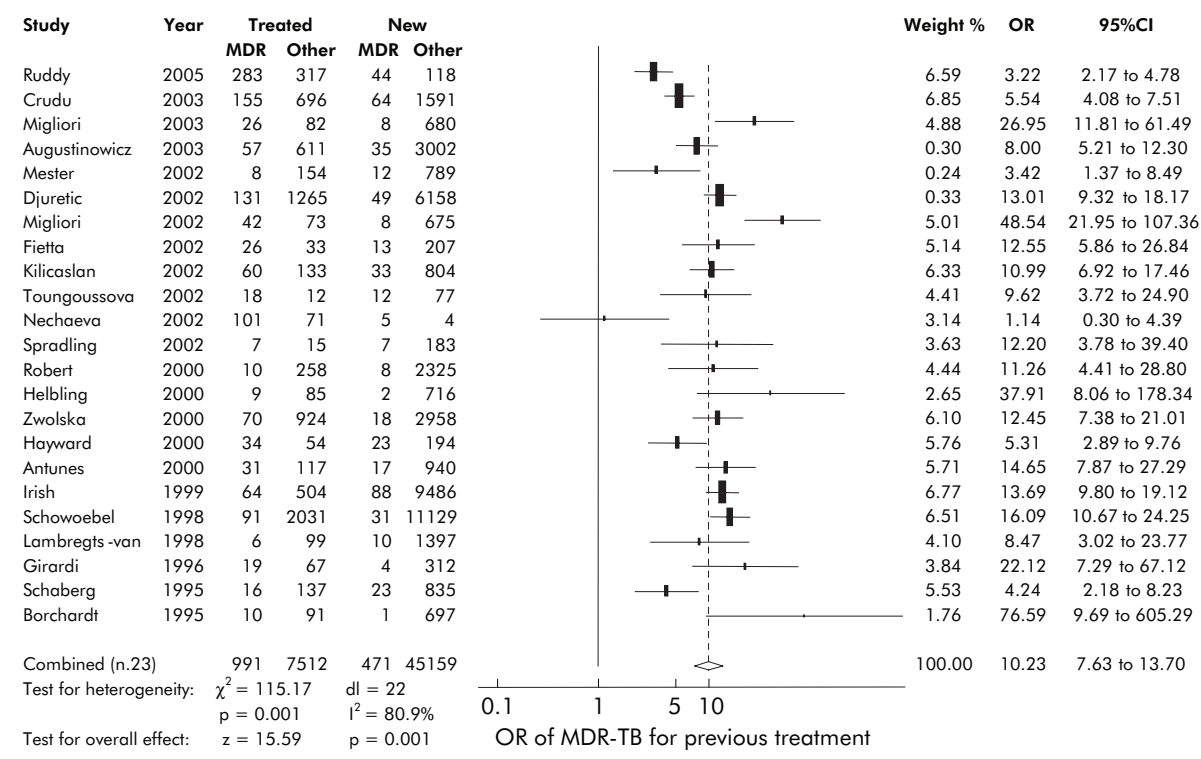

Figure 1 Odds ratio (OR) of multidrug resistant tuberculosis (MDR-TB) for previous treatment in Europe.

databases. Two additional papers were identified from a manual search of International Journal of Tuberculosis and Lung Disease and four from references in other papers. Out of 125 studies reviewed in full, 29 were selected for the review on the basis of the inclusion criteria. Five studies ${ }^{14-18}$ were excluded from the meta-analysis because they did not report complete data on which the pooled risk estimates were calculated. They are reported in table 1 , together with two other papers included in the meta-analysis that did not report complete data for some risk factors.

Twelve European countries were represented in the review: the former USSR, ${ }^{19-23}$ Poland, ${ }^{24}{ }^{25}$ Hungary, ${ }^{26}$ and Turkey ${ }^{27}$ from eastern Europe; Italy, ${ }^{28-31} \mathrm{UK}^{, 32-34}$ France, ${ }^{35} 36$ Switzerland, ${ }^{37} \quad$ Spain, $^{38} \quad$ Portugal, $^{39}$ Netherlands $^{40}$ and Germany $^{41}{ }^{42}$ from western Europe. The studies were carried out between 1984 and 2000, and the number of cases studied ranged from 119 to 25217 . Chronic TB was included in three studies, ${ }^{20} 2326$ explicitly excluded in one, ${ }^{32}$ and may or may not have been included in 20 papers. All the studies were prospective or retrospective surveys; nine were laboratory based, 10 population based, and five hospital based. The relative risk estimates were reported in six population based and two laboratory based surveys.
MDR-TB patients were more likely to have received previous treatment in 22 studies, with a pooled risk estimate 10 times higher for treated than for new patients; the association was weak and not significant ${ }^{22}$ in only one study (fig 1); one additional study did not analyse this factor. ${ }^{38}$

The European area $(p=0.004)$ and the study design $(p=0.04)$ were associated with the risk estimates of MDRTB for previously treated patients, while no relation was found with the proportion of patients who were male, younger than 45, HIV positive, foreign born, or the year in which the TB occurred.

We could calculate national pooled risk estimates of MDRTB for treated patients only in six countries: the former USSR (OR 4.64), Italy (OR 24.56), Poland (OR 9.72), the UK (OR 10.55), France (OR 15.19), and Germany (OR 15.17). The pooled risk estimates for previously treated patients were lower in eastern Europe (OR 6.35; 95\% CI 4.27 to 9.49) than in western Europe (OR 13.99; 95\% CI 10.19 to 19.21 ).

The pooled risk estimates for previously treated patients was a little lower when estimated through the ORs in all studies (OR 10.23; 95\% CI 7.63 to 13.70) than when estimated through RRs in the eight cohort studies (RR 12.02 ; $95 \%$ CI 8.11 to 17.81 ).

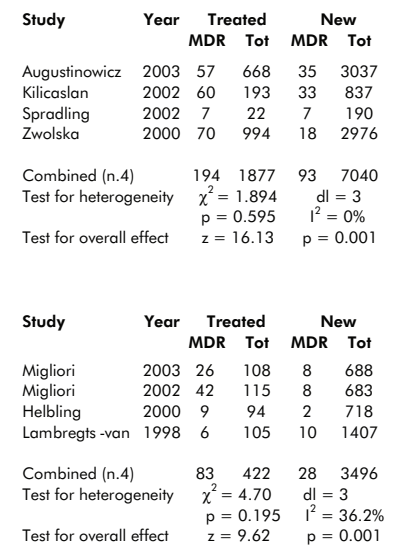

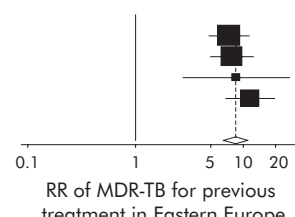

treatment in Eastern Europe

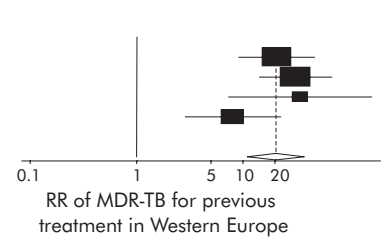

Figure 2 Relative risk of multidrug resistant tuberculosis (MDR-TB) in western and eastern Europe. 


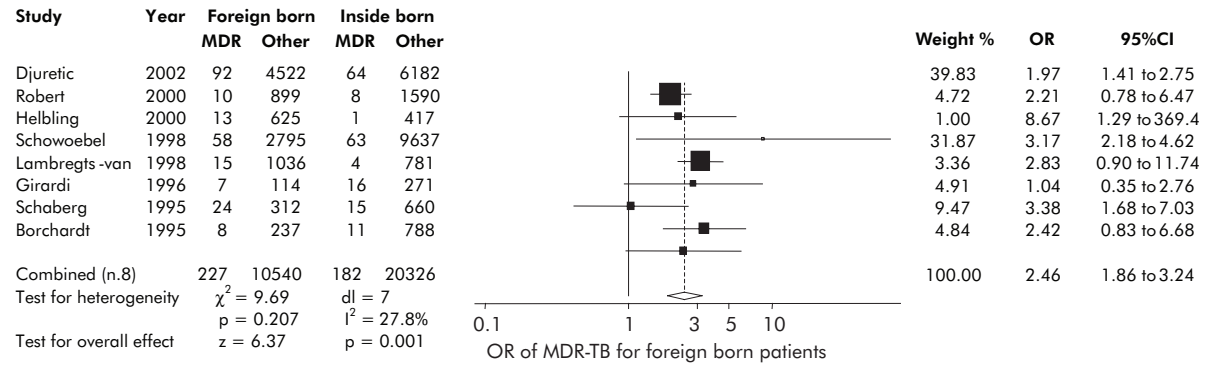

Figure 3 Odds ratio (OR) of multidrug resistant tuberculosis (MDR-TB) for foreign born patients.

Neither location nor study design explained the heterogeneity between the studies. Heterogeneity was only explained when pooled MDR-TB risk was estimated in studies that used both a cohort design and analysed differences in risk by European area (fig 2).

MDR-TB patients were more likely to be foreign born in eight studies carried out in western Europe, although one study did not find any association between foreign status and MDR-TB $^{31}$ (fig 3). Foreign status was not analysed at all in 15 studies, including all nine performed in eastern Europe. An additional study explicitly excluded foreign born patients. ${ }^{25}$

No association was found between the risk of the MDR-TB individual being foreign born and the proportion of patients who were male, younger than 45 years, HIV positive or previously treated, the year the TB occurred, or the study design.

MDR-TB patients were more likely to be younger than 65 years (fig 4). The pooled risk of MDR-TB for people younger than 45 was lower (OR 1.52; 95\% CI 1.13 to 2.03 ). Only five of the eight studies 22323436 that analysed age under 45 found an association, and the heterogeneity remained very high. MDR-TB patients were more likely to be male; heterogeneity between the studies was low although only three studies showed a clear association with male sex (fig 4). We found a stronger association with male sex (OR $1.54 ; 95 \%$ CI 1.31 to 1.82 ) in the eight studies carried out in western Europe and heterogeneity between studies very low $(p=0.956)$. Men were at lower risk of MDR-TB in the three studies carried out in the former USSR (OR 0.86; 95\% CI 0.43 to 1.71) with a high heterogeneity between studies $\left(\chi^{2}=6.53 ; p=0.04\right)$.
MDR-TB patients were more likely to be HIV positive (fig 5), although one study in France ${ }^{35}$ and one in Italy ${ }^{31}$ did not find any association with this variable, and in a further study $^{36}$ the association was limited to new cases. Sixteen studies did not analyse this factor at all and one other excluded HIV positive patients. ${ }^{25}$

Finally, MDR-TB was associated with being a prisoner in the five studies which included prisoners (OR 1.75; 95\% CI 0.90 to 3.40). The estimated risk of MDR-TB for prisoners was studied more frequently in countries of the former Soviet Union than in the rest of Europe.

\section{DISCUSSION}

\section{Limitations of this study}

The most important limitation of the study is the large number of papers with missing data on risk factors. Fifteen papers did not provide information on age, 16 did not report foreign status, and 12 did not list the sex of the study subjects. The large heterogeneity observed for the pooled estimate of MDR-TB in previously treated patients is likely to be due to methodological differences between the studies, such as different referent groups, misclassification of new and previously treated cases, and the inclusion of chronic cases.

There were sufficient studies on imprisonment to calculate the pooled risk factor. Other social factors such as homelessness ${ }^{16}$ and urban residence ${ }^{22}$ were reported in very few papers, although they were found to be associated with MDR-TB. Unemployment, ${ }^{1621}$ alcohol abuse, ${ }^{14} 162140$ low education, ${ }^{14}$ and low socioeconomic status ${ }^{17}$ were not found to be associated with MDR-TB. A more precise definition of
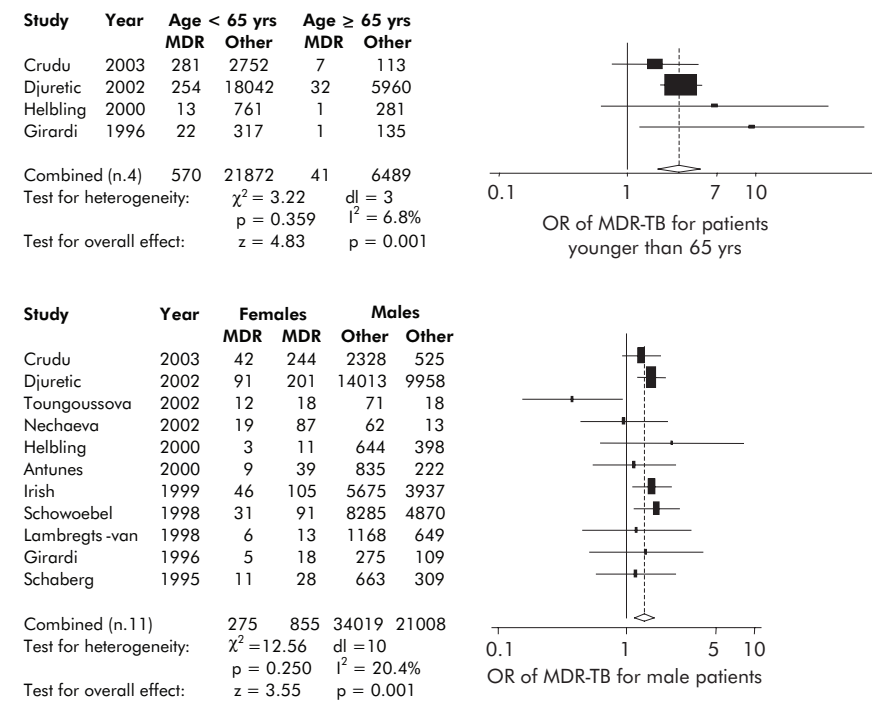

younger than $65 \mathrm{yrs}$

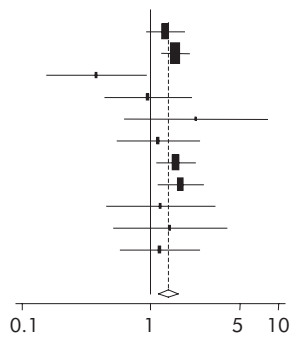

OR of MDR-TB for male patients
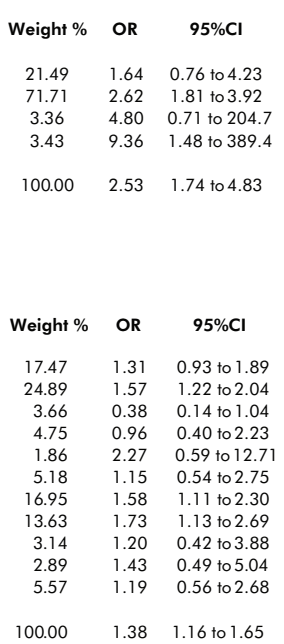

$100.00 \quad 1.38 \quad 1.16$ to 1.65

Figure 4 Odds ratio (OR) of multidrug resistant tuberculosis (MDR-TB) for age $<65$ years and male sex in Europe. 


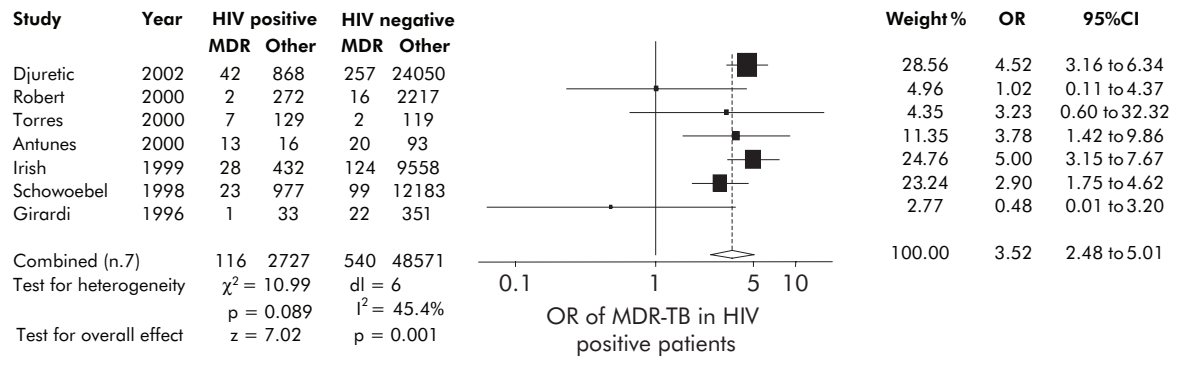

Figure 5 Odds ratio of multidrug resistant tuberculosis (MDR-TB) for HIV positive patients.

these risk factors is desirable to test their impact on MDR-TB.

\section{Effect of treatment}

Previous treatment has been widely recognised as inducing multidrug resistance of $M$ tuberculosis and the prevalence of MDR-TB has been estimated to be up to 10 times higher after unsuccessful treatment. ${ }^{8}$ Even in this review, previous treatment was the strongest risk factor for MDR-TB in Europe, but it showed peculiar characteristics. The higher risk observed in western than in eastern Europe was probably due to the higher prevalence of newly diagnosed MDR-TB in eastern Europe, but the strength of the association we observed in western Europe was twice as high as that expected. Values as high as 31.18 and 34.37 were found in Italy $^{29}$ and in Germany, ${ }^{37}$ respectively. These observations strongly suggest the need for analysis of determinants of inadequate treatment. Delayed diagnosis, delayed recognition of drug resistance, inappropriate chemotherapy regimens, inadequate or irregular drug supply, and poor compliance by both patients and clinicians have each been reported as a reason for inadequate treatment. ${ }^{68}$ Only a few studies in this review specified the reasons for inadequate treatment-for example, defaulting treatment, ${ }^{21}$ receiving previous treatment in prison, ${ }^{23}$ and being given fewer than four drugs. ${ }^{22}$

Geographical distribution and study design explained the heterogeneity observed between the studies in risk of MDRTB by previous treatment. However, these results were reported in only eight of the 23 studies and other factors not explored here could have contributed to the differences observed. Firstly, the risk estimates for previous treatment were obtained in most studies comparing MDR-TB with sensitive and other drug resistant TB, but a few used other referent groups such as patients infected with strains resistant to multiple drugs other than $\mathrm{HR}^{22}$ or isoniazid. ${ }^{33}$

Secondly, chronic cases should have been analysed separately because it is very unlikely that the risk factor that caused MDR-TB is identified. A chronic case has been defined by the WHO as a patient who is sputum positive at the end of a retreatment regimen. Even though some studies tried to exclude chronic patients, ${ }^{32}$ verifying these criteria is difficult, especially in surveys based on routine data, while other studies explicitly included chronic TB. ${ }^{20} 2326$ Their inclusion may have erroneously increased the risk of MDR-TB observed for previous treatment in western countries.

A third problem is the possible misclassification of cases with respect to previous treatment. Misclassification may occur when patients do not reveal previous TB. ${ }^{43}$ Since a history of TB may be more actively sought in those with known resistance, this can lead to differential misclassification. ${ }^{13} 2031{ }^{43}$ Even in prospective surveys, previous TB is likely to be denied by older patients or illegal immigrants. ${ }^{26}{ }^{32}{ }^{34}{ }^{35} \mathrm{~A}$ patient could have already been infected with a multidrug resistant strain of $M$ tuberculosis at the time of previous treatment, and/or a re-infection with a resistant strain may have occurred independent of the first episode of $\mathrm{TB}^{43}$
Molecular analysis can be used to estimate possible clinical misclassification. In South Africa the percentage of resistant TB in new cases was estimated to be $52 \%$ by restriction fragment length polymorphism (RFLP) but only $29 \%$ on the basis of clinical history. ${ }^{44}$

Finally, selection bias was possible in studying TB patients for drug sensitivity as these patients were chosen by clinical criteria. Studying representative samples of all TB patients could reduce this selection bias. ${ }^{8}$

\section{Influence of immigration}

Immigration has been suggested as one factor leading to the increased prevalence of MDR-TB in European countries. ${ }^{45}$ This review found that MDR-TB patients were more likely to be foreign born, although the strength of the association was much less than for previous treatment. The association between MDR-TB and being foreign born could be due to a higher risk of transmission of MDR strains of $M$ tuberculosis for immigrants, but it may be confounded by previous treatment. Although we could not analyse how many foreign born patients were newly diagnosed or previously treated, a few studies in this review dealt with this problem. A French study stratifying results by country of birth found a higher risk of MDR-TB in both new and previously treated patients from sub-Saharan Africa, while patients from North Africa were at higher risk of MDR-TB only after a previous treatment. ${ }^{36}$ In the UK, cases treated abroad were found to be at higher risk of MDR-TB than those treated nationally, regardless of birthplace. ${ }^{33}$ These results suggest that previous treatment may be the most important risk factor for MDR-TB in immigrants as well as in natives, and underline the importance of controlling for this in analysing the risk of migration.

\section{Role of age and sex}

There was a clear association observed between MDR-TB and age under 65 years, but the association was weak and more heterogeneous for ages under 45 . This result could reflect the year in which effective anti-tuberculosis drugs such as rifampicin were introduced. ${ }^{8}$

MDR-TB patients were more likely to be male in western Europe, where previous treatment was the most important determinant of MDR-TB. In eastern Europe, where the risk of transmission is greater, male sex was not a risk factor for MDR-TB. Although we did not find any influence of sex on the association between MDR-TB and previous treatment, we cannot exclude an effect of sex in modifying the association between previous treatment and MDR-TB. It could be hypothesised that women are more compliant with treatment and therefore less likely to receive inadequate treatment.

\section{Role of HIV}

Initially it seemed that HIV status was a risk factor for MDRTB, but nosocomial outbreaks largely accounted for the association and, currently, the prevalent hypothesis is that 
HIV infection favours the transmission of multidrug resistant strains of $M$ tuberculosis. ${ }^{46}$ Although one study of the five reviewed showed that MDR-TB patients were more likely to be HIV positive only when they were new TB cases, ${ }^{36}$ we think it unlikely that HIV positive patients were treated inadequately more frequently than others.

The pooled risk of MDR-TB we observed for HIV status could have been affected by a selection bias occurring in favour of HIV infected individuals among cases studied for sensitivity. This hypothesis is supported by the high proportions of HIV patients (32-52\%) among those studied for drug sensitivity, ${ }^{38}{ }^{39}$ which is unlikely to reflect the actual prevalence of HIV among TB cases.

In conclusion, although some characteristics of TB treatment such as defaulting from treatment are well known predictors of multidrug resistance, other aspects of treatment such as the drugs used and the length of treatment need to be studied as they may contribute to improving control programmes. Analysing immigrants by specific country of origin, timing of immigration and previous treatment would help to define the risk of MDR-TB associated with immigrants. Molecular epidemiology can minimise misclassification of previous TB treatment, but its most important contribution to the epidemiology of MDR-TB will come from understanding the dynamics of transmission, especially between geographic areas, and by distinguishing exogenous infection from endogenous reactivation.

\section{ACKNOWLEDGEMENTS}

The authors thank Margaret Becker for the English revision, Roberta Macci for the support in finding the original papers, and Sarah Pennisi for her help with the figures.

\section{Authors' affiliations \\ A Faustini, C A Perucci, Department of Epidemiology, Local Health Agency RME, Rome, Italy}

A J Hall, Department of Infectious and Tropical Disease, London School of Hygiene and Tropical Medicine, London, UK

Competing interests: none declared.

The list of papers excluded from the meta-analysis is available in Word format on request.

\section{REFERENCES}

1 Centres for Diseases Control. Tuberculosis: United States. First 39 weeks, 1985. MMWR 1985;34:625-7.

2 Raviglione $M$, Sudre $P$, Rieder $\mathrm{HL}$, et al. Secular trends of tuberculosis in Western Europe. WHO Bull 1993;71:293-306.

3 Rieder HL, Cauthen GM, Comstock GW, et al. Epidemiology of tuberculosis in the United States. Epidemiol Rev 1989;11:79-98.

4 McKenna MT, McCray E, Onorato I. The epidemiology of tuberculosis among foreign-born persons in the United States, 1986-1993. N Engl J Med 1995;322:1071-6.

5 Frieden TR, Sterling T, Pablos-Mendez A, et al. The emergence of drugresistant tuberculosis in New York City. N Eng J Med 1993;328:521-6.

6 World Health Organisation. Anti-tuberculosis drug resistance in the world, WHO Report No 3. Geneva: World Health Organisation, 2004.

7 Globe M, Iseman MD. Madsen LA, et al. Treatment of 171 patients with pulmonary tuberculosis resistant to isoniazid and rifampin. N Engl J Med 1993;328:527-32.

8 Pablo-Méndez A, Raviglione MC, Laszlo A, et al. Global surveillance for antituberculosis-drug resistance, 1994-1997. N Engl J Med 1998;338:1641-9.

9 Teixeira L, Perkins MD, Johnson JL, et al. Infection and disease among household contacts of patients with multidrug-resistant tuberculosis. Int $J$ Tuberc Lung Dis 2001;5:321-8.

10 Snider DE, Kelly GD, Cauthen GM, et al. Infection and disease among contacts of tuberculosis cases with drug-resistant and drug-susceptible bacilli. Am Rev Respir Dis 1985;132:125-32.

11 Pfyffer GE, Strassle A, von Gorkum T, et al. Multidrug-resistant tuberculosis in prison inmates, Azerbaijan. Emerg Infect Dis 2001;7:855-61

12 Frieden TR, Woodley CL, Crawford JT, et al. The molecular epidemiology of tuberculosis in New York City: the importance of nosocomial transmission and laboratory error. Tuberc Lung Dis 1996;77:407-13.

13 Pablo-Mendez A, Lessnau K. Clinical mismanagement and other factors producing antituberculosis drug resistance. In: Bastian I, Portaels F, eds.
Multidrug-resistant tuberculosis. Netherlands: Kluwer Academic Publishers, 2000:55-76

14 Lockman S, Kruuner A, Binkin NJ, et al. Clinical outcomes of Estonian patients with primary multidrug-resistant versus drug-susceptible tuberculosis. Clin Infect Dis 2001;32:373-80.

15 Gilad J, Borer A, Riesenberg K, et al. Epidemiology and ethnic distribution of multidrug-resistant tuberculosis in southern Israel, 1992-1997. The impact of immigration. Chest 2000;117:738-43.

16 Anon. Primary multidrug-resistant tuberculosis: Ivanovo oblast, Russia, 1999. MMWR 1999;48:661-3.

17 Flament-Saillour M, Robert J, Jarlier V, et al. Outcome of multidrug-resistant tuberculosis in France. A nationwide case-control study. Am J Respir Crit Care 1999:160:587-93.

18 Kimerling ME, Slavuckii A, Chavers S, et al. The risk of MDR-TB and polyresistant tuberculosis among the civilian population of Tomsk city, Siberia, 1999. Int J Tuberc Lung Dis 2003;7:866-72.

19 Ruddy M, Balabanova Y, Graham C, et al. Rates of drug resistance and risk factor analysis in civilian and prison patients with tuberculosis in Samara Region, Russia. Thorax 2005;60:130-5.

20 Crudu V, Arnadottir Th, Laticevschi D. Resistance to anti-tuberculosis drugs and practices in drug susceptibility testing in Moldova, 1995-1999. Int J Tuberc Lung Dis 2003;7:336-42.

21 Toungoussova OS, Caugant DA, Sandven $P$, et al. Drug resistance of Mycobacterium tuberculosis strains isolated from patients with pulmonary tuberculosis in Archangels, Russia. Int J Tuberc Lung Dis 2002:6:406-14.

22 Nechaeva OB, Skachkova El, Fomina NI. Drug resistance of Mycobacterium tuberculosis in the Sverdlovsk region [in Russian]. Probl Tuberc 2002;9:8-11.

23 Spradling $P$, Nemtsova E, Aptekar T, et al. Anti-tuberculosis drug resistance in community and prison patients, Orel oblast, Russian federation. Int J Tuberc Lung Dis 2002;6:757-62.

24 Augustynowicz-Kopec E, Zwolska Z, Jaworski A, et al. Drug-resistant tuberculosis in Poland in 2000: second national survey and comparison with the 1997 survey. Int J Tuberc Lung Dis 2003;7:645-51.

25 Zwolska Z, Augustynowicz-Kopec E, Klatt M. Primary and acquired drug resistance in Polish tuberculosis patients: results of a study of the national drug resistance surveillance programme. Int J Tuberc Lung Dis 2000;4:832-8.

26 Mester J, Vadasz I, Pataki G, et al. Analysis of tuberculosis surveillance in Hungary in 2002. Int J Tuberc Lung Dis 2002;6:966-73.

27 Kilicaslan Z, Albal H, Kiyan E, et al. Drug resistance in pulmonary tuberculosis in Istanbul. Eur J Clin Microbial Infect Dis 2002;21:763-4.

28 Migliori GB, Centis R, Fattorini L, et al. Monitoring the quality of laboratories and the prevalence of resistance to antituberculosis drugs: Italy, 1998-2000. Eur Respir J 2003;21:129-34

29 Migliori GB, Fattorini L, Vaccarino P, et al. Prevalence of resistance to antituberculosis drugs: results of the 1998/99 national survey in Italy. Int J Tuberc Lung Dis 2002;6:32-8.

30 Fietta A, Cascina A, Meloni F, et al. A 10-year survey of Mycobacterium tuberculosis isolates in Pavia and their drug resistance: a comparison with other Italian reports. J Chemother 2002;14:33-40.

31 Girardi E, Antonucci G, Tronci $M$, et al. Drug resistance patterns among tuberculosis patients in Rome, 1990-1992. Scand J Infect Dis 1996:28:487-91.

32 Diuretic T, Herbert J, Drobniewski $F$, et al. Antibiotic resistant tuberculosis in the United Kindom: 1993-1999. Thorax 2002;57:477-82.

33 Hayward AC, Herbert J, Watson JM. Tuberculosis drug resistance in England and Wales. How much is "home-grown"? Epidemiol Infect 2000;125:463-4.

34 Irish C, Herbert J, Bennett D, et al. Database study of antibiotic resistant tuberculosis in the United Kindom, 1994-6. BMJ 1999;318:497-8.

35 Robert J, Trystram D, Truffot-Pernot C, et al. Surveillance of Mycobacterium tuberculosis drug resistance in France, 1995-1997. Int J Tuberc Lung Dis 2000;4:665-72.

36 Schwoebel V, Decludt B, de Benoist A-C, et al. Multidrug resistant tuberculosis in France 1992-4: two case-control studies. BMJ 1998;317:630-1.

37 Helbling P, Altpeter E, Raeber P-A, et al. Surveillance of antituberculosis drug resistance in Switzerland 1995-1997: the central link. Eur Respir J 2000;16:200-2.

38 Torres L, Arazo P, Perez JB, et al. Resistencia de Mycobacterium tuberculosis en Zaragoza (1993-1997) y factores asociados. Med Clin 2000;115:605-9.

39 Antunes ML, Aleixo-dias J, Antunes AF, et al. Anti-tuberculosis drug resistance in Portugal. Int J Tuberc Lung Dis 2000;4:223-31.

40 Lambregts-van Weezenbeek CSB, Jansen HM, Nagelkerke NJD, et al. Nationwide surveillance of drug-resistant tuberculosis in the Netherlands: rates, risk factors and treatment outcome. Int $J$ Tuberc Lung Dis 1998:2:288-95.

41 Schaberg T, Glober G, Reichert B, et al. Drug-resistant pulmonary tuberculosis in Berlin, Germany, 1987-1993. Eur Respir J 1995;8:1067.

42 Borchardt J, Kirsten D, Jorres R, et al. Drug-resistant tuberculosis in Northern Germany: a retrospective hospital-based study of 1055 patients from 1984 until 1993. Eur Respir J 1995;8:1076-83.

43 Rieder HL. Drug-resistant tuberculosis: issues in epidemiology and challenges for public health. Tuberc Lung Dis 1993;75:321-3.

44 Van Rie A, Warren R, Richardson $M$, et al. Classification of drug-resistant tuberculosis in an epidemic area. Lancet 2000;356:22-5.

45 Espinal MA, Laszlo A, Simonsen L, et al. Global trends in resistance to antituberculosis drugs. N Engl J Med 2001;344:1294-303.

$46 \mathrm{McCray} E$, Onorato $I M$. The interaction of human immunodeficiency virus and multidrug-resistant Mycobacterium tuberculosis. In:Bastian I, Portaels F. Multidrug-resistant tuberculosis. Netherlands: Kluwer Academic Publishers, 2000:45-57. 